DOI: 10.11606/issn.2318-8855.v7i7p209-233

\title{
Análise Comparativa do Uso das Imagens em Livros Didáticos com Conteúdo de História Medieval
}

\author{
Mariana Rodrigues de Vita* \\ Thalita Mota da Silva** \\ Sarah Cafe Santos ${ }^{* *}$
}

Resumo: Este artigo tem como objetivo investigar a abordagem de História Medieval em livros didáticos como um documento histórico. Foram escolhidos três livros destinados a alunos de ensino médio e a metodologia utilizada consiste na análise da composição e do conteúdo das páginas, levando em conta haver ou não uma relação pertinente entre imagens e textos.

Palavras-Chaves: Livro Didático; História Medieval; Análise Comparativa.

\section{Introdução}

Este trabalho busca analisar o uso de imagens no conteúdo de História Medieval de livros didáticos. Para isso, utilizamos os livros "Estudos de História, v.1", dos autores Ricardo de Moura Faria, Mônica Liz Miranda e Helena Guimarães Campos, do ano de 2010, editora FTD; "A Escrita da História", de Flávio de Campos e Regina Claro, do ano de 2009, editora Escala

\footnotetext{
${ }^{*}$ Graduanda de História na Universidade de São Paulo (USP). Faz parte do grupo de pesquisa Mulheres na América Portuguesa e do grupo de estudo de História da África, coordenado pela prof. Maria Cristina Wissenbach. E-mail: marianadevita@usp.br

${ }^{* *}$ Graduanda de História na Universidade de São Paulo (USP). E-mail: thalita.ms@usp.br

${ }^{* * *}$ Graduanda de História na Universidade de São Paulo (USP). Faz parte do grupo de estudo de História da África coordenado pela prof. Marina de Mello e Souza. E-mail: sarahcafe@usp.br
} 


\section{artigos}

\section{Mariana Rodrigues de Vita, Thalita Mota da Silva e Sarah Cafe Santos}

Educacional; e, por fim, o "Livro-texto: Anglo - História (Ensino Médio)", de Diego Lopez Silva, Gianpaolo Dorigo e Renan Garcia Miranda, do ano de 2016, SOMOS Sistemas de Ensino.

Os três livros foram escolhidos primeiramente por terem em comum a faixa etária: todos são destinados a alunos de ensino médio. No entanto, foram também consideradas as particularidades de cada um: por exemplo, o livro "A Escrita da História" é um volume único, enquanto os outros dois são segmentados. Além disso, a escolha avaliou a divergência de contexto entre eles, sendo que um é destinado à escola pública (Estudos de História), outro à escola particular (A Escrita da História) e por fim um voltado às escolas particulares com projetos pedagógicos que visam estritamente os vestibulares (Livro-texto: Anglo), sendo os dois últimos inseridos, portanto, em contextos socioeconômicos de classe média e classe alta. Assim, os livros pertencem a um grupo amplo, de livros para ensino médio, mas com divergências na base do estudo.

O estudo de caso a partir dos três livros escolhidos se propõe a gerar reflexões sobre como os livros didáticos utilizam determinada pedagogia diante de limitações da própria materialidade do livro, como questões de espaço na página ou até mesmo número de páginas, com questões práticas e teóricas que levam em consideração como determinado processo histórico será tratado nas variadas idades dos alunos. Diante desses objetivos mais amplos, o artigo tem como foco entender as relações imagem-texto apresentadas nos livros didáticos, se há uma preocupação em usar as imagens como documentos históricos, complexificando seu entendimento enquanto material documental e enquanto arte ou se o uso da imagem se dá de forma estritamente ilustrativa, não se conectando aos textos de forma complementar e embasada, levando em consideração que o conjunto material e teórico tem como público determinada camada socioeconômica. Logo, este artigo trabalhará a observação da dicotomia entre as imagens entendidas como para consumo rápido ou como objetos de discussão. 


\section{artigos}

Análise Comparativa do Uso das Imagens em Livros Didáticos com Conteúdo de História Medieval

Assim, utilizamos conceitos - como o da teoria das funções da imagem, de RodríguezDiéguez - para classificar as funções didáticas das figuras presentes no conteúdo de História Medieval dos livros já citados e dessa forma identificar questões como a de hierarquia e autonomia entre texto e imagem, que, assim como as atividades relacionadas às imagens, indicam, por exemplo, se elas são tratadas como documento histórico ou ornamento, o que influencia na forma como o aluno se relacionará com a imagem, conseguindo ou não absorver todo o conhecimento que uma imagem pode carregar. Para isso, nosso fundamento teórico se dá essencialmente a partir dos estudos de Circe Bittencourt e Bárbara Barros Olim.

De forma comparativa, buscamos entender o livro didático em suas múltiplas funções: tanto referenciais (para o programa de ensino), como instrumentais (para facilitar a memorização, por exemplo) e documentais, seguindo conceitos trabalhados por Alan Chopin (CUNHA; XAVIER, 2011, p.125). No entanto, foi preciso levar em consideração que existe conforme comentado por Erica Xavier e Maria de Fátima da Cunha - uma complexa relação entre os poderes da sociedade, do Estado, das editoras e da Academia que se chocam muitas vezes devido às disputas de narrativa, condicionando a produção e o conteúdo dos livros didáticos; logo, estes livros não são neutros, são "um espaço de lutas de representações, de narrativas vencedoras" (CUNHA; XAVIER, 2011, p.124-125), sendo tais representações diretamente ligadas ao presente, já que o livro se constrói como um espaço predominado pelas elites, com seus projetos políticos, culturais e de valores, além de sua própria identidade e noção de cidadania, atuando assim junto às editoras como uma indústria cultural (CUNHA; XAVIER, 2011, p.127).

A análise se baseou em um roteiro de questões elaboradas com base na bibliografia, a partir das quais foram redigidos os textos de análise individual dos livros e em seguida a comparação, onde procuramos tratar de similaridades e disparidades entre eles, além de padrões ideológicos ou usos didáticos em relação à utilização das imagens. O roteiro de questões levantadas engloba ainda o enfoque em sujeitos sociais - como é tratada a questão 


\section{artigos}

\section{Mariana Rodrigues de Vita, Thalita Mota da Silva e Sarah Cafe Santos}

das mulheres na Idade Média, por exemplo -, se o autor busca tratar a História de forma multifacetada e interdisciplinar (levando em consideração política, economia, cultura, etc.), assim como se existe a intenção de sair da zona de conforto, seja por meio de imagens que não estão no imaginário coletivo ou pela transgressão de estereótipos como o da "Idade das Trevas".

\section{Livro A Escrita da História (Flávio de Campos e Regina Claro, 2009 - Escala educacional)}

Todas as imagens no livro são coloridas, o papel é de boa qualidade e reflete a luz, o que as faz aparecer de forma viva e brilhante. Todos esses fatores somados tornam mais prática e interessante a visualização das figuras, que ocupam espaços variados, desde quase uma página inteira até uma miniatura. O livro é atraente justamente pela combinação desses diversos fatores como cores brilhantes, imagens grandes e fundos coloridos, e, diante de tantas características, ele deixa de ser barato (OLIM, 2010, p.95). Como é um livro datado de 2009, atualmente já perdeu seu preço no mercado, mas está reformulado segundo o acordo ortográfico da época, o que também contribui para o aumento de seu valor, fazendo com que o público alvo se restrinja as escolas particulares e alunos com poder aquisitivo considerável.

O livro não trata de forma multifacetada os sujeitos sociais, assim como não mostra uma heterogeneidade dentro dos grupos, já que há uma escolha em tratar a Idade Média através da macrovisão política. A própria religiosidade, um dos pilares para o entendimento da Idade Média, é pouco explorada no que se refere a imagens. As mulheres também estão no grupo social que é marginalizado pelas imagens, já que são absolutamente tratadas como figurantes em quase todas as representações.

Elas raramente possuem sua presença representada e, quando isso acontece, estão em contexto de casamento, banquete ou como participante do sistema de trabalho feudal. As únicas personagens que ganham protagonismo nas imagens são Eva - que está representada com a maçã diante da serpente, em uma iluminura que mostra o pecado original - e a Virgem 


\section{artigos}

Análise Comparativa do Uso das Imagens em Livros Didáticos com Conteúdo de História Medieval

Maria - representada no contexto da Anunciação, com Jesus em seus braços. Diante desse quadro de ausência da figura feminina fora dos espaços já compreendidos, o aluno pode entender que a mulher se reduzia aos lugares e tipos ideais que o autor apresenta (LOHN; MACHADO, 2004, p.122). Não existe um questionamento sobre quem produziu as imagens que são apresentadas. Mesmo considerando que na Idade Média a autoria tenha sido uma questão - como discute Jean Claude Schmitt (2007, p.293), no capítulo 8 de sua obra “O Corpo das Imagens" -, o livro não aborda a problemática que girou em torno dos artistas mundanos produzindo imagens sagradas (talvez, por ser um livro destinado ao ensino médio, o autor tenha considerado tal questão um tema além do que deveria ser cobrado e entendido). No que se refere ao entendimento das imagens na época, há um pequeno texto, que ocupa dois parágrafos apenas, em que é explicado o que são ícones, imagens de culto e a importância dos ornamentos, no entanto, o autor também não elabora sugestões de perguntas ou textos sobre qual a intencionalidade das imagens, o que elas representam ou porque são feitas de tal forma, o que elevaria a complexidade das mesmas (LITZ, 2009, p.2), além de colocá-las em um ponto de estudo no qual imagem equivale a documento. Existem divisões observáveis já no índice: a Idade Média é posta na segunda unidade (nomeada "Idade Média, Idade dos Homens"), sendo que a primeira é sobre a Antiguidade - que, segundo o livro, termina com a queda do Império Romano - e expõe uma frase de Lucien Febvre: “A Europa surge quando o Império desmorona".

Existem ainda subdivisões dentro da própria unidade: ela é dividida em dois capítulos, sendo que o primeiro apresenta uma quantidade superior de mapas, abordando a formação territorial, e no segundo as imagens que mais se encontram são iluminuras. Pouco se mostra sobre arquitetura, fotografias de locais ou de documentos, esculturas, etc. Os autores optam por trazer no primeiro capítulo o enfoque geográfico da formação dos Impérios, para depois tratar sobre a história social, e, em meio a outros elementos, o fenômeno espiritual, que, segundo Sofia Boesch Gajano, é um fenômeno de múltiplas dimensões e importância crucial para o entendimento do período (2002, p.449), mas não existe uma abordagem que o 


\section{artigos}

\section{Mariana Rodrigues de Vita, Thalita Mota da Silva e Sarah Cafe Santos}

contemple de forma aprofundada durante a unidade. Usando como referência o artigo de Bárbara Olim (2010, p.99-108) - que se baseia na teoria das funções da imagem, de Rodríguez-Diéguez - podemos classificar a maioria das imagens presentes no material analisado como possuidoras de função facilitadora, vicarial e motivadora, já que estão simbioticamente conectadas a um texto que não modificaria seu sentido na ausência delas, mas que complementam o aprendizado do estudante. Em relação às legendas, pode-se dizer que elas são essenciais para o entendimento das figuras, já que possuem informações como data, título, tipo de imagem e algumas vezes contam a história daquilo que a imagem retrata, ou seja, são legendas de referência (OLIM, 2010, p.110). As legendas são sucintas, já que as reflexões se encontram nos textos adjacentes - que são uma divagação em relação ao texto principal e estão inseridos em um fundo de tom amarelado -, aos quais as imagens se referem diretamente como forma de ilustração. Existe um exercício de final de unidade que propõe a análise do quadro "O jardim das delícias terrenas" de Hieronymus Bosch, pintado no século XV. Este painel foi escolhido porque, para Jacques Le Goff, o quadro era uma síntese do imaginário medieval. As perguntas são sugestões de como analisá-lo e são bem abertas, como, por exemplo: "relacionar o quarto plano à religiosidade medieval". Há também outro exercício, contendo duas imagens em tamanho grande e que propõe a comparação entre uma escultura denominada Mater Dolorosa do século XIV e a Pietà de Michelangelo (14981499). Existe um total de 23 questões nesse capítulo, entretanto, somente esses dois exercícios apresentam imagens.

O uso didático das imagens condiz com a faixa etária dos alunos - já que não há imagens infantis -, assim como propõe desafios, a exemplo do pedido para interpretar uma pintura no exercício de fechamento do capítulo ("O jardim das delícias terrenas" de Bosch, que já mencionamos). Entretanto, o livro não parece tratá-las como documento histórico (exceto nos exercícios), já que as imagens são um instrumento pedagógico em uma relação vertical com os textos, ou seja, há uma submissão na importância do tratamento das figuras em relação às palavras escritas, já que as imagens são como um instrumento de tornar concreta uma ideia dissertada no texto (BUENO, 2011, p.68-70). Os mapas, no entanto, não participam 


\section{artigos}

Análise Comparativa do Uso das Imagens em Livros Didáticos com Conteúdo de História Medieval

dessa lógica, já que o texto é que se subordina a eles.

O livro não trata as imagens no que se refere a questões estéticas: técnicas de pintura ou escultura que remetessem a época, ou questionamentos sobre porque essa obra foi criada dessa forma, se ela foi feita para ressaltar um ideal ou uma situação; assim como não tem questionamentos de para quem foi feita a obra e por quem (seja grupo social ou artista). Há informações rasas e factuais nas legendas como a data de criação da obra, mas não existe a intenção de desenvolver a reflexão artística do aluno - discutindo estilo histórico, simbolismo ou técnica, por exemplo (LITZ, 2009).

As imagens sempre agem de forma comprobatória com relação aos textos, portanto não existem conflitos entre eles que possam gerar quebra de expectativa ou ampliação da noção de complexidade da realidade. Os créditos das imagens se encontram logo abaixo das mesmas, entretanto não há nenhum tipo de referência adicional ao final do livro, assim como não há sugestões de outros tipos de imagens ou veículos para expansão do assunto, como documentários, filmes, músicas, HQs, entre outros. Logo na capa percebe-se que o livro tem mais de um autor: Flávio de Campos, professor de História Medieval da Universidade de São Paulo, mestre e doutor em História Social e Regina Claro, doutoranda em educação na Universidade de São Paulo. Ambos fazem parte do grupo que trabalha a iconografia do livro, junto de Maria Alice Bragança (coordenação), Luis Sérgio Colombo e Neuza Faccini. Há um grupo separado para a confecção dos mapas, portanto é perceptível o cuidado na apresentação de imagens e na relação delas com os textos. Porém, as partes editoriais, de mercado, edição, revisão, coordenação de arte, projeto gráfico e diagramação, dentre outras, são trabalhadas por diferentes profissionais, que por mais que conversem entre si ainda constroem o livro de maneira fragmentada e da forma mais rentável possível, já que se trata de um produto (BITTENCOURT, 2015, p.71 e 73). 


\section{artigos}

\section{Mariana Rodrigues de Vita, Thalita Mota da Silva e Sarah Cafe Santos}

Dado o exposto, podemos concluir que existe uma preocupação em utilizar imagens coerentes com a proposta dos capítulos e do tema, mas a falta de questionamentos que iriam interferir diretamente na noção de verdade histórica e documental é algo a ser notado - não é possível saber se por uma exigência editorial, de mercado ou por uma opção dos autores. Em relação à interpretação de imagens o livro deixa muito a desejar, já que o único indicativo de tal análise se dá em apenas dois exercícios. Os simbolismos que as imagens contêm e a sua importância no contexto histórico são postos de modo secundário, o que levanta a hipótese das imagens atuarem como uma bengala dos textos.

\section{Livro Estudos de História v.1 (Ricardo de Moura Faria, Mônica Liz Miranda e Helena Guimarães Campos, 2010 - FTD)}

Este livro selecionado para ser analisado tem como público-alvo os alunos da $1^{\text {a }}$ série do Ensino Médio. Sua divisão é feita em dez partes, sendo elas: "Orientações de Estudo", seis unidades que abordam grandes temas de história, "Sugestões de leituras complementares para os alunos", "Sugestão de sites" e "Sugestões de filmes e documentários". A terceira unidade, a qual nos é objeto de estudo, "A Europa Medieval", apresenta seis capítulos de subtemas, sendo eles: "O cristianismo, a Igreja e os reinos bárbaros", "Os mundos de Bizâncio e do Islã", "Economia, sociedade e política no feudalismo", "O desenvolvimento do comércio e o crescimento urbano", "Religiosidade, mentalidades e vida cultural" e "Crise e transformações nos séculos XIV e XV", além de dois dossiês ("África" e "História \& Cidadania") e um capítulo de exercícios. É interessante ressaltar que, na introdução desta unidade, é explicitada uma discordância em relação à visão da Idade Média como "Idade das Trevas" e no decorrer dos capítulos é possível ver que essa discordância se mantém e se torna mais evidente ainda nos dois últimos, onde se trata da produção cultural da Europa Ocidental.

Não se fala muito sobre questões como as cruzadas, a peste negra, as guerras ou a grande influência da Igreja - essa última tenta-se relativizar. Talvez seja por esse motivo que o livro não trate muito a respeito da religiosidade cristã - ao menos na unidade em análise - o que explica a reduzida presença de imagens com temática bíblica em seu conteúdo. Das 57 


\section{artigos}

Análise Comparativa do Uso das Imagens em Livros Didáticos com Conteúdo de História Medieval

imagens da unidade, apenas quatro apresentam essa questão, sendo elas: três fotografias de vitrais (cujo foco se dá à questão arquitetônica, não ao conteúdo dos vitrais) e uma iluminura da Ressurreição de Cristo do "Livro de horas do Duque de Berry", mas que só aparece como um "exemplo de uma iluminura", conforme se apresenta em sua legenda (FARIA; MIRANDA; CAMPOS, 2010, p.120), num contexto onde são discutidas as artes na Idade Média, sendo que no texto da página não há menção a iluminuras. Nos seus seis capítulos, a unidade apresenta pouca profundidade quanto aos assuntos tratados e também quanto às imagens presentes. Somente o primeiro mapa é mencionado no decorrer do texto, pois retrata as invasões bárbaras ao Império Romano Ocidental, apresentando os povos germanos, que só vem a ter seus nomes distinguidos no texto no momento em que esse aborda o reino dos Francos. Tal imagem assume, então, função informativa e vicarial (OLIM, 2010). As demais imagens da unidade não são mencionadas nos textos que acompanham. A unidade "A Europa Medieval" tem 48 páginas e 57 imagens, ou seja, uma razão de 1,18 imagens por página. Entretanto, essa grande quantidade de imagens não significa que elas são tratadas como documento, pois raramente o são; em verdade, há sessões para intepretação de "documento escrito" e de "documento literário" (denominações dadas pelo livro), mas não há o uso da palavra "documento" para referir-se às imagens na unidade.

Existem atividades sobre imagens fora do capítulo voltado para os exercícios e uma questão (entre os exercícios) que utiliza uma tirinha. Das 56 imagens (aqui não contando a tirinha), existem 11 atividades relacionadas a 11 imagens, contendo uma questão simples em cada, sendo que 8 delas são de leitura e interpretação e 3 são de interpretação. Segundo Barbara Barros de Olim (2010, p.109), “é nesse tipo de atividade [leitura e interpretação] que o aluno trata a imagem como um texto imagético e é impulsionado para a alfabetização visual". Entretanto, essas atividades por si só, não levam o estudante a interpretar/analisar profundamente as imagens, pois as questões a elas referentes se prendem a elementos superficiais. 


\section{artigos}

\section{Mariana Rodrigues de Vita, Thalita Mota da Silva e Sarah Cafe Santos}

Em geral, as imagens da unidade representam elementos presentes nos textos, mas sem acrescentar informações ou propor algum debate, o que limita a interpretação a ser feita delas, pois dentre as 57 imagens, 46 delas cumprem função facilitadora, e as demais funções ocorrem em menor número, não ultrapassando uma dezena cada (uma vez que as imagens podem ter mais de uma função). Ainda segundo Barbara Barros de Olim (2010, p.100): “A função facilitadora redundante está quase sempre presente quando utilizamos imagens juntamente com texto, funcionando como complemento ou reforço da informação textual, pois, não só ilustra o conteúdo claramente manifestado no texto, mas também auxilia no entendimento e na atenção dada á página, pelo leitor". Pode-se entender que o principal objetivo nesse grande uso de imagens e suas posições em relação aos textos seja tornar o ato da leitura mais fácil e interessante para o aluno. Essas imagens variam entre pintura, fotografia, mapa, ilustração, iluminura, gravura, miniatura, afresco, manuscrito, escultura, mosaico e tirinha. Com temáticas variando entre situação de belicosidade, religião islã, arquitetura, comércio ou comerciante, camponeses, nobres, populares (festa popular), universidade, medicina, escultura, mapas, religião cristã, peste negra, Joana d'Arc, etc.

As imagens que retratam mulheres como figuras de maior importância (onde ela é identificável por seu gênero, e não representada apenas como parte de um bloco social) são duas: a da imperatriz Teodora, esposa de Justiniano, oferecendo um cálice de ouro à igreja e de Joana d'Arc sendo amarrada a um tronco para ser queimada. Não há relação de submissão ou estereótipo, talvez por ambas estarem em posições relevantes. Há outras cinco imagens onde é possível identificar a figura feminina, entretanto, nessas, elas estão apenas como parte de um grupo social, como camponês ou nobre. As legendas repetem informações dos textos e explicam do que se trata a imagem, mas, por vezes, também trazem informações adicionais ao contexto do que é representado imageticamente, e ainda há algumas figuras que são totalmente dependentes da legenda para que seu conteúdo seja compreendido.

Em suma, há uma hierarquia na unidade, onde as imagens são usadas em função de facilitar a leitura dos textos e atrair a atenção do aluno. Mas para isso, a interpretação 


\section{artigos}

Análise Comparativa do Uso das Imagens em Livros Didáticos com Conteúdo de História Medieval

imagética não é incentivada. O fato é que há uma deficiência significativa ao não se agregar às imagens o seu valor como documento histórico, o que gera um prejuízo ao aluno. Essa falha do livro só pode ser recompensada com a iniciativa do professor.

\section{Livro Livro-texto: Anglo - História (Diego Lopez Silva, Gianpaolo Dorigo e Renan Garcia Miranda, 2016 - SOMOS Sistemas de Ensino)}

O último livro a ser analisado é pertencente ao Sistema Anglo, por isso diverge um pouco mais dos outros dois em seu formato. É um livro leve, com as páginas mais largas do que o usual, além de não ser dividido em unidades, e sim em dezessete capítulos. O livro tem como público alvo estudantes da $1^{\text {a }}$ série do ensino médio provavelmente de escolas particulares que priorizam a preparação para os vestibulares, já que pertence ao Sistema Anglo. É apenas um "livro-texto", ou seja, não possui exercícios. Os alunos de escolas que utilizam esse material possuem para a matéria de História três materiais separados, um voltado apenas para textos (que é o que está sendo analisado), um apenas de exercícios e outro de resumos, além de uma plataforma digital com conteúdo diverso.

Nesta análise, vamos nos ater ao livro-texto, porque não tivemos acesso aos outros materiais, que são exclusivos para alunos e professores. Em uma análise mais técnica do uso das imagens no material, é válido dizer que elas são todas coloridas e seus tamanhos variam, mas não há nenhuma de tamanho tão reduzido a ponto de prejudicar sua compreensão (com certeza seria algo benéfico se os estudantes tivessem acesso apenas a imagens grandes, para analisá-las em detalhes, mas isso não seria prático para a organização do livro, além de não ser essencial).

Antes de partir para a análise direta das imagens, há algumas considerações sobre o material como um todo que consideramos importantes. O livro não discute questões como a do conceito de Antiguidade Tardia, mas cita que existem diversas formas de dividir historicamente os dez séculos correspondentes ao período medieval, alertando que usualmente seu início é marcado pela queda do Império Romano em 476, embora existam 


\section{artigos}

\section{Mariana Rodrigues de Vita, Thalita Mota da Silva e Sarah Cafe Santos}

divergências (que não são levantadas). Além disso, ele utiliza a divisão clássica de Alta (séc. VX) e Baixa (séc. XI-XV) Idade Média, mas avisa que essas divisões são eurocêntricas e não muito adequadas para pensar na trajetória de outras civilizações como a bizantina e a islâmica.

No primeiro capítulo a respeito da Idade Média, o livro cita brevemente o fenômeno da iconoclastia no Império Bizantino, e conclui que, apesar disso, o conceito de imagens com caráter pedagógico (objetivo de educar os fiéis) será o que prevalecerá. O autor traça ainda, no mesmo capítulo, um paralelo entre a questão iconoclasta bizantina e a proibição de imagens religiosas também existente na formação do islamismo, citando um trecho relativamente longo da obra "A História da Arte", do estadunidense Horst Waldemar Janson, que fala sobre a condenação de Maomé à idolatria, ressaltando que esse aspecto se dava em relação às estátuas, enquanto as pinturas e outros modos de representação tem interpretação ambígua e mais complexa (SILVA; DORIGO; MIRANDA. 2016, p.58). Assim como no caso de H.W. Janson, há outros momentos em que o livro traz citações diretas de historiadores ou historiadores da arte, principalmente para comentar imagens dentro de boxes com temas específicos.

Há imagens que estão dentro de boxes temáticos (temas como patrimônio cultural e artístico, questões de gênero, o papel da floresta na sociedade medieval, entre outros) acompanhadas de textos que exploram o mesmo tópico, mas nem sempre se referem diretamente à imagem. Muitas vezes, é nesses boxes que estão as citações diretas de historiadores e historiadores da arte que já foram comentadas.

Quanto às legendas de todas as imagens do material analisado, pode-se observar que, na maioria das vezes, elas são sintéticas e se limitam a localizar a obra ou imagem no tempo e no espaço e explicitar o que está acontecendo em algumas delas.

Para um aluno preocupado em memorizar o conteúdo, como ocorre entre os prévestibulandos, as representações gráficas e sucintas de um texto auxiliam muito na fixação 


\section{artigos}

Análise Comparativa do Uso das Imagens em Livros Didáticos com Conteúdo de História Medieval

do conteúdo, logo, podemos considerar que já que o Sistema Anglo é intimamente ligado a empresas de cursos pré-vestibular, esse é um aspecto que será valorizado em todos os seus livros.

Percebemos que as fotografias também são muito utilizadas, principalmente para trazer imagens referentes à arquitetura. Em seguida vêm as iluminuras e pinturas. As pinturas, iluminuras, afrescos, gravuras, entre outros tem suas técnicas citadas muito brevemente. $\mathrm{O}$ contexto histórico geralmente é dado, mas a procedência (quem fez, quando, onde, porque, para quem) é mais rara, talvez pela falta de informações, talvez por não considerá-las essenciais. A maior ênfase geralmente é dada à explicação de o que ocorre na cena. Assim como no caso dos mapas, todos os outros tipos de imagens são comumente utilizados como representação de algo geral. Ao analisar todo o conjunto de figuras, foi possível concluir que existe predomínio das funções vicarial e facilitadora, principalmente desta última. Vale notar ainda que no caso dos mapas, as funções geralmente são também catalisadoras e explicativas.

O último capítulo dentre os que atendem a temática medieval é nomeado "Cultura medieval". É interessante citá-lo aqui porque o mesmo traz uma discussão a respeito de diversos setores da cultura, tais como as letras, as universidades, a filosofia, o pensamento e as artes plásticas, então era esperado que fosse dada uma atenção especial às imagens. De fato, houve maior disposição do autor em analisar melhor as imagens em dois momentos: primeiro ao trazer uma iluminura do século XIV e finalmente explicar ao aluno na legenda o que são as iluminuras e, por último, ao apresentar uma figura alemã que mostrava o fim de uma justa, pela primeira vez o livro irá comentar uma imagem em termos de analisá-la de fato, falando em perspectiva e inexpressividade. Mas a discussão acerca das cenas desse último capítulo parece ainda ser mais em torno dos textos do que das imagens, estas, por sua vez, são no geral ilustrações do conteúdo, com legendas curtas. 


\section{artigos}

\section{Mariana Rodrigues de Vita, Thalita Mota da Silva e Sarah Cafe Santos}

É importante ressaltar que aqui novamente o livro traz uma reflexão acerca do préjulgamento que muitas vezes ocorre da produção imagética medieval por esta apresentar "cenas que parecem pouco realistas" e "personagens inexpressivas" (SILVA; DORIGO; MIRANDA. 2016, p.89): o autor destaca que o objetivo da pessoa que produzia aquela imagem não era mostrar a realidade e nem mostrar o que achava dela, a ideia central era estimular a espiritualidade, isto é, "o conteúdo ou sentido da imagem deveria ser construído pelo observador e apenas sugerido pelo artista" (SILVA; DORIGO; MIRANDA. 2016, p.89). Esse caráter era o mesmo quando se tratava de imagens profanas.

No livro, é possível perceber que, apesar de as legendas datarem as obras medievais, essa datação é muito ampla. Frequentemente uma imagem será creditada a um século específico, o que é um período temporal muito grande; isso provavelmente ocorre porque é difícil determinar a origem particular de cada obra. Também se pode pensar nas imagens que foram escolhidas para serem usadas no material: a maioria delas foi produzida durante a Idade Média, o que demonstra uma preocupação do autor em mostrar de fato a forma como o período era visto por aqueles que o viveram. Porém, há algumas figuras feitas posteriormente, como no caso do retrato de São Tomás de Aquino, de Sandro Botticelli. Podemos concluir, então, que algumas imagens são ilustrações do texto, e não do período, o que não é um problema, já que tudo isso está especificado nas legendas e até porque o autor demonstra consciência disso e até mesmo chega a comentar que uma das imagens trazidas pelo livro (uma iluminura do século XV que representa a conquista de Constantinopla pela Quarta Cruzada) seria um tanto quanto anacrônica, já que o autor da imagem não teria presenciado o fato retratado (as muralhas estilizadas parecem com um castelo europeu) (SILVA; DORIGO; MIRANDA. 2016, p.67).

O consumo das imagens acaba sendo rápido e superficial na maioria dos casos, mas essa proposta didática parece condizer com os objetivos de um aluno de ensino médio ou vestibulando, que possuem um volume considerável de informações para guardar. Os textos não são longos nem cansativos e possuem vários subtítulos, o que convém para o método de 


\section{artigos}

Análise Comparativa do Uso das Imagens em Livros Didáticos com Conteúdo de História Medieval

ensino proposto pelo Sistema Anglo, que tem por parâmetros os vestibulares. O conteúdo é bastante pontuado, o texto não faz referências diretas às imagens, mas elementos citados rapidamente no texto são desenvolvidos indiretamente por elas, como acontece, por exemplo, quando o material apresenta uma foto da catedral de Santa Sofia (que só tem o seu nome dito no texto) acompanhada de uma legenda que detalha suas dimensões e a classifica historicamente (SILVA; DORIGO; MIRANDA. 2016, p.52).

Em algumas ocasiões acontece de a imagem vir antes do texto apresentando algo que ainda será dito, como uma espécie de introdução, porém não muito desenvolvida. Pode haver também a possibilidade de uma figura aparecer acrescentando uma informação que não é dada pelo texto em momento algum, ou seja, funciona como um complemento importante e que deve ser observado. Mas, em alguns momentos, essas imagens independentes também carecem de informações na legenda, o que é ruim, já que o texto também não se refere a elas, apesar de se relacionarem tematicamente e, com isso, elas não ficam muito bem estabelecidas.

Em virtude do que foi mencionado, podemos concluir que o uso das imagens neste livro muitas vezes serve para ilustrar os textos e concretizar seus dados, ou seja, existe uma hierarquia entre texto e imagem, na qual para entender o contexto da segunda, é necessário, na maioria das vezes, que o estudante compreenda o primeiro. Pode acontecer de o texto e a imagem trazerem a mesma informação, quase que completamente (como ocorre com alguns mapas). Porém, em alguns momentos, são as ilustrações que irão acrescentar um comentário a mais, além de que elas fixam o conteúdo de forma diversa da do texto. Levando em consideração esses aspectos, se pode entender que ambos se complementam e são, majoritariamente, apresentados de forma harmoniosa.

\section{Análise comparativa dos três materiais didáticos selecionados:}

Antes de entender o panorama histórico em que os livros se inserem e discutir as questões que foram observadas em cada um deles de forma comparativa, é interessante 


\section{artigos}

\section{Mariana Rodrigues de Vita, Thalita Mota da Silva e Sarah Cafe Santos}

levantar brevemente a história dos livros didáticos em contextos políticos e culturais distintos: o livro didático chega ao Brasil no século XIX - apenas para as elites, no Colégio Dom Pedro II - e sua abordagem, neste momento, contemplava as histórias de grandes nomes e heróis, preferencialmente. No entanto, a partir do surgimento da imprensa, a produção de livros foi notavelmente barateada e, juntamente a um projeto nacional de alfabetização, foi inserido um número considerável de pessoas no mundo educacional. O livro passara de um ideal de manual para uma construção devidamente pedagógica. É significativo fazer referência à Era Vargas e ao período Ditatorial Militar, nos quais a dominação intelectual consequente de projetos políticos específicos é abordada como um reflexo do próprio momento. No período de redemocratização, no entanto, o PNLD (Programa Nacional do Livro Didático) implementa a Lei 91.542, que incorpora ideais democráticos, mais uma vez demonstrando a relação entre o período histórico e os materiais didáticos. Por mais que, desde 1996, muitos professores tenham passado a escolher os livros didáticos a serem utilizados em suas aulas, o Estado ainda tem um grande poder decisivo na qualificação e crítica dos livros, já que essa é uma área de muito investimento e que gera altíssimo lucro às editoras (assumindo assim sua dimensão mercadológica), estas por sua vez se adequam ao olhar determinado e estatal da História (CUNHA; XAVIER, 2011, p.128). Além disso, em muitas escolas, como é o caso das municipais, muitas vezes o professor não é quem escolhe os livros (OLIVEIRA, 2016, p. 87).

Os materiais didáticos analisados neste artigo, no entanto, encontram-se entre os livros de contexto cultural dos anos 2000, no qual há um considerável crescimento em relação à quantidade de imagens utilizadas. No geral, os livros se enquadram na História Tradicional, que leva em conta a temporalidade eurocêntrica, ao contrário da História Renovada, que é tratada por temáticas que colocam a História Política de modo integrado e não exclusivo, aguçando assim não só o pensamento crítico, mas a visão multifacetada da História (OLIVEIRA, 2016, p.90). Após a análise individual dos três livros (sendo o critério de escolha inicial dos mesmos a faixa etária, já que todos são destinados ao ensino médio), nota-se que cada um tem uma proposta didática diferente para retratar a Idade Média, seja na escolha do 


\section{artigos}

Análise Comparativa do Uso das Imagens em Livros Didáticos com Conteúdo de História Medieval

que desenvolver e sintetizar em relação aos temas seja na escolha das imagens apresentadas; sendo assim, é possível aproximar ou distanciar diversos aspectos entre os livros. No que se refere às imagens, é crível que as escolhas das mesmas atuarão como um instrumento pedagógico, mas também como um atrativo rentável. O livro em si já traz limitações por reunir diversos conteúdos tentando aprofundá-los o máximo possível em apenas algumas páginas, então o autor tem que fazer escolhas difíceis a respeito do que priorizar diante dos seus próprios valores e referências historiográficas e pedagógicas.

Diante desse cenário, serão analisados alguns aspectos como: quebra de paradigmas imagens que se comportam no contexto como um instrumento para transgredir estereótipos -, proposta didática, ou seja, critérios na utilização de imagens e dados técnicos do livro e, por último, a contextualização e uso das imagens.

No que se refere à questão da representação imagética da mulher, o livro do Anglo possui um box no capítulo 11 nomeado "Questões de gênero", que contém uma iluminura que representa Cristina de Pisano, uma intelectual e poetisa. O texto ao qual a imagem faz referência disserta sobre as mulheres como grupo social na época das grandes cortes surgidas na Idade Média e como a mentalidade vigente refletia o seu papel na sociedade, mostrando assim uma preocupação em situar as mulheres em posições mais centrais e colocando em reflexão a mentalidade contemporânea de ver a mulher medieval como uma figura homogênea e de completa submissão. Uma situação semelhante é visível no livro Estudos de História, que contém imagens de mulheres ocupando um espaço de centralidade e protagonismo: são elas a Imperatriz Teodora e Joana d'Arc.

No livro A Escrita da História, entretanto, essa questão se coloca de maneira diferente. Nele, a mulher faz parte de um grupo marginalizado nas imagens, sempre aparecendo em um contexto de figurante, como trabalhadora ou em um banquete ao lado da figura principal que geralmente é o rei ou o papa; as únicas mulheres que tem destaque são: Eva, segurando a maçã em frente à serpente (não ocupando a totalidade ou centralidade da imagem, já que 


\section{artigos}

\section{Mariana Rodrigues de Vita, Thalita Mota da Silva e Sarah Cafe Santos}

há também Adão representado) e a Virgem Maria, no contexto da Anunciação e segurando o menino Jesus. Os três livros, em se tratando de imagens de sujeitos sociais da Idade Média, convergem para a proposta didática de macrovisão política, tratando os indivíduos de forma secundária, não retratando a realidade complexa e multifacetada, levando também em consideração o limite pequeno de páginas para tratar de assuntos tão vastos.

Passando para o outro item de comparação, a questão das propostas didáticas, primeiramente foi analisado como cada livro propôs uma divisão de capítulos diferentes segundo sua proposta interna; o livro Anglo trata o assunto fragmentado entre Alta e Baixa Idade Média, e possui capítulos específicos de feudalismo, cruzadas, renascimento e formação das monarquias. O livro parte da ideia de que a Idade Média começou com a queda do Império Romano, entretanto coloca que existem diversas formas de se dividir o período historicamente, e alerta que usa a cronologia mais usual mesmo ela sendo eurocêntrica e não tão apropriada para os bizantinos ou islâmicos.

Considerável quantidade de capítulos também é apresentada no livro Estudos de História, com uma unidade dividida em seis capítulos e ainda um dossiê sobre a África; diferentemente do livro A Escrita da História, que se mostra mais abrangente ao dividir a unidade em apenas dois capítulos sendo que o primeiro é chamado de "Alta Idade Média", mesmo que este não venha seguido de outro chamado "Baixa Idade Média".

De modo geral, todos os livros aqui analisados fazem um trabalho de qualidade em relação a intercalar imagens entre colunas ou demais lugares estratégicos para que a leitura, que já pode ser considerada desafiadora pela complexidade do conteúdo, funcione de modo pragmático. Sendo assim, os textos são curtos e existem diversas marcações visuais para separá-los e dar ênfase; também não há nenhum elemento corrompendo o entendimento das imagens ou dos textos de forma relevante.

Além do mais, a legenda também funciona como elemento facilitador para compreensão da imagem, entretanto, ocorre de modo diverso nos livros: no Estudos de 


\section{artigos}

Análise Comparativa do Uso das Imagens em Livros Didáticos com Conteúdo de História Medieval

História e no Livro-texto Anglo não há um padrão referente às legendas, ou seja, algumas imagens apresentam legendas sintéticas, com informações referentes à data, autor, etc., enquanto outras vezes a imagem não vem acompanhada de legenda ou possui uma extensa legenda explicativa; o livro A Escrita da História possui sempre uma legenda sintética que acompanha todas as imagens, mas muitas vezes elas não possuem dados referentes a datas, locais, dimensões ou outras informações do tipo.

A qualidade das imagens também se torna um critério de avaliação entre os livros: todos os três possuem imagens coloridas que tornam o aluno capaz de analisar melhor e com mais detalhes as figuras, além de possuírem, na maioria das vezes, um bom tamanho, levando em consideração a harmonia entre todo o conteúdo e a quantidade de páginas a ele reservado.

Ainda sobre como os livros abordam as questões imagéticas, é notável a questão das atividades e exercícios (considerando que o livro do Anglo possui um livro de exercícios independente do livro-texto, ao qual não se teve acesso): no livro Estudos de História, existem 11 questões que são atreladas às imagens, entretanto não propõem uma análise e tratamento aprofundado sobre elas especificamente. Já no livro A Escrita da História, há apenas dois exercícios durante a unidade que contém imagens, contudo, elas protagonizam as questões sendo postas como documento histórico a ser entendido.

O modo como os livros conduzem os exercícios sem figuras é um reflexo de como as imagens são entendidas e retratadas durante os capítulos. Em nenhum dos três livros podese dizer que houve uma preocupação em destrinchar muitas das imagens, pontuando a visão do autor e ideologia que está retratada, tal como não existe um aprofundamento em relação ao entendimento da imagem num contexto histórico, mergulhado em determinado tipo de técnica e nem sua procedência, ou seja, quem foi o autor, de onde veio à imagem, porque e para quem ela foi feita, etc. E se o livro por si só possui limitações referente à utilização de imagens que tem que lutar para ocupar espaços do texto e vice-versa, os livros aqui 


\section{artigos}

\section{Mariana Rodrigues de Vita, Thalita Mota da Silva e Sarah Cafe Santos}

analisados não indicaram sugestões audiovisuais e de outras imagens fora do livro, com exceção do livro Estudos de História.

A maioria esmagadora das imagens nos três livros possui função facilitadora, portanto os textos aos quais elas se relacionam podem ser entendidos sem a presença da imagem, que aparece como uma forma de reafirmar o que foi dito, tornando mais visível o conceito e para ajudar na memorização. Existe uma hierarquia presente nos livros que põe a imagem para ser tratada de forma rápida e superficial e em posição mais baixa em relação ao texto no que concerne à apresentação de conhecimento. Assim, na maior parte das vezes, o texto será o detentor principal das informações. A seguir, apresentamos o gráfico que oferece um comparativo entre os tipos e quantidades de imagens em cada um dos materiais didáticos analisados: 


\section{artigos}

Análise Comparativa do Uso das Imagens em Livros Didáticos com Conteúdo de História Medieval

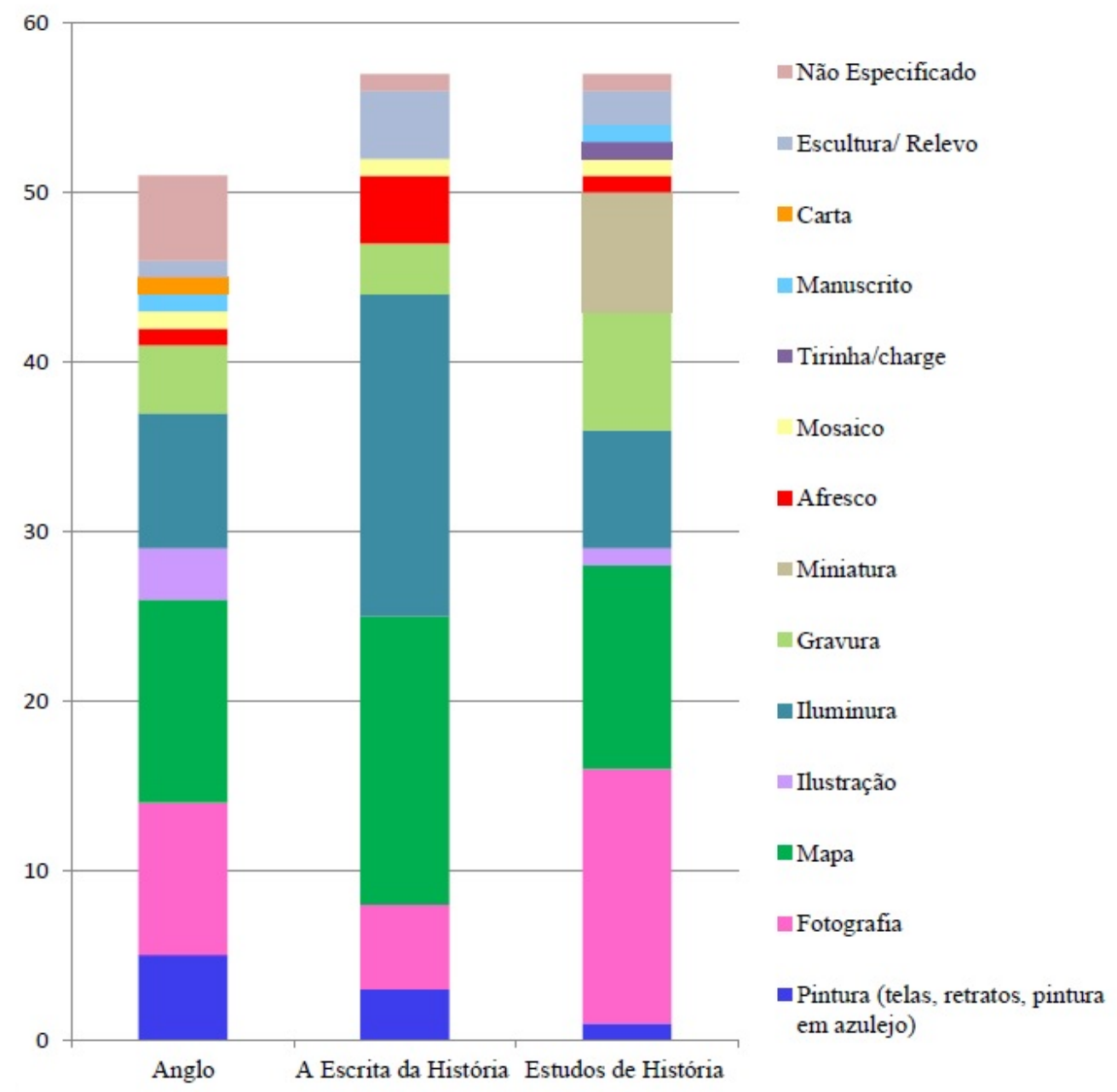

Gráfico 1: comparativo quantitativo de imagens presentes em cada livro analisado. No geral, todos os livros possuem muitas imagens, no entanto os tipos diferem entre si de acordo com cada proposta pedagógica e limitações editoriais.

Diante do gráfico é possível concluir, portanto, que os livros utilizam diversos tipos de imagens. O livro do Anglo, talvez por ser de uma empresa fortemente ligada aos vestibulares, preza pela praticidade e velocidade em fornecer os conteúdos, já que precisa pontuar os assuntos que mais caem no vestibular além de tratar da História em si de modo mais facilitador e cronológico possível, portanto, tal como nos demais livros, existe uma presença massiva de mapas, que são imagens que contém em si uma quantidade extensa de 


\section{artigos}

\section{Mariana Rodrigues de Vita, Thalita Mota da Silva e Sarah Cafe Santos}

informações de forma visual, objetiva e pragmática. Existe também um equilíbrio na distribuição dos diversos tipos de imagens que não se encontra presente nos livros Estudos de História e A Escrita da História, sendo que o primeiro contém uma quantidade considerável de fotografias e o segundo de iluminuras.

No entanto, mesmo com essas divergências, todos os livros possuem uma quantidade de imagens praticamente igual, sendo que o Livro-texto Anglo possui 51, e, os demais, 57 imagens durante os capítulos de Idade Média.

Esse comparativo revela, portanto, que os livros, no geral, são parecidos em diversos aspectos como na quantidade de imagens e nas funções que elas exercem no entendimento do assunto, mas existem diferenças em se tratando de quais tipos de figuras são as mais utilizadas e quais os temas e pessoas que as protagonizam.

\section{Conclusão:}

Durante a realização da presente pesquisa, foi possível observar que as imagens nos livros didáticos podem ter variadas funções: podem ser um instrumento pedagógico facilitador, uma ilustração direta ou complementar dos textos, um documento a ser analisado, uma forma de memorização ou fixação do conteúdo, dentre outras multifunções. Esses papéis podem ocorrer de forma simultânea ou ser priorizados de acordo com os objetivos dos autores. Nos materiais didáticos analisados, é possível que uma ou mais funções tenham sido consideradas durante o processo de curadoria. Além disso, há ainda os casos nos quais imagens específicas são utilizadas com propósitos singulares, como acontece no livro "A Escrita da História" com o uso do tríptico "O Jardim das Delícias Terrenas" de Hieronymus Bosch, que é bastante pedagógico ao propor o entendimento da Idade Média a partir de sua análise e reflexão, estimulando o aluno a prestar atenção especial à imagem.

O livro é uma materialidade da sociedade contemporânea, portanto pode ser estudado como documento, e, sendo assim, partimos do estudo de cada um dos livros escolhidos para entender como as escolhas historiográficas, políticas e pedagógicas se 


\section{artigos}

Análise Comparativa do Uso das Imagens em Livros Didáticos com Conteúdo de História Medieval

relacionam com a sociedade e são recebidas em sala de aula, dando atenção especial à forma como foram selecionadas as imagens. Ficou atestado que muitos fatores influenciam a publicação de um livro didático, e, no caso das imagens, ainda deve se considerar a questão dos direitos autorais, as viabilidades de venda e o que deve ser priorizado levando em consideração as limitações financeiras.

Portanto, se faz necessário entender e refletir acerca da complexidade do livro didático, que atualmente possui uma dimensão global: como produto cultural, didático e mercadológico, que reflete mudanças da sociedade através do tempo - suas políticas, ideologias, debates, seu mercado e muitos outros aspectos que impactam na produção desse material.

Os livros analisados absorveram influências da chamada Nova História, que a partir dos anos 90 trouxe maior diálogo com outras áreas das ciências humanas, inseriu no debate sujeitos tradicionalmente marginalizados e alargou o foco dos estudos com a introdução de temas como História das Mentalidades e do Cotidiano. Também passaram a utilizar novas fontes, que não apenas documentos escritos. Essas mudanças se refletiram nos livros didáticos, uma vez que o mercado editorial participou ativamente das discussões da época. No entanto, vale ressaltar que apesar das mudanças que trouxe a Nova História, ainda hoje encontramos fortes resquícios do eurocentrismo nos livros didáticos que se utilizam da história integrada, mantendo a temporalidade tradicional, mesmo que com ressalvas, como é o caso do "Livro-texto: Anglo", que alerta os alunos sobre a inadequação da periodização utilizada, mas a utiliza mesmo assim.

Escolher como contar a História é um ato político que é reflexo de uma indústria cultural social de grupos específicos que utilizam o livro didático como um instrumento para levar seus valores e ideias (BITTENCOURT, 2015) atuando como um veículo de controle discursivo (FERRARO, 2011, p.173). É sempre válido se pensar na forma como as imagens são usadas nos materiais didáticos e quais os efeitos que elas produzem no contato com os 


\section{artigos}

\section{Mariana Rodrigues de Vita, Thalita Mota da Silva e Sarah Cafe Santos}

estudantes, pois elas também são documentos históricos e devem ser valorizadas como tal. E apesar do Estado, da Academia e da editora serem elementos que estão intimamente ligados entre si no processo de produção do livro didático, não podemos esquecer o consumidor final: a escola. Se o que muitas vezes ocorre é que em sala de aula utiliza-se o livro como referência única, entendemos que dessa forma se limita a experiência de aprendizado que o aluno poderia ter, com a utilização do livro como documento, por exemplo, para desenvolver o pensamento crítico, desenvolvendo também a autonomia do estudante. Ou seja, é necessário atribuir ao livro mais do que a função referencial (CUNHA; XAVIER, 2011, p.125).

\section{Livros Didáticos:}

CAMPOS, Flavio de; CLARO, Regina. A Escrita da História. 2. ed. São Paulo: Escala Educacional, 2009. cap. 5-6, p. 128-191. V. único.

FARIA, Ricardo de Moura; MIRANDA, Mônica Liz; CAMPOS, Helena Guimarães . Estudos de História. FTD, 2010. Unidade 3, v.1.

SILVA, Diego Lopez; DORIGO, Gianpaolo; MIRANDA, Renan Garcia. ANGLO - História - Livrotexto. São Paulo: SOMOS, 2016. cap. 7-13, p. 51-90.

\section{Referências Bibliográficas:}

BAIRRO, Catiane Colaço de. Livro didático: um olhar nas entrelinhas da sua história. Disponível em: <www.histedbr.fae.unicamp.br/acer_histedbr/.../Cj5GgE6L.doc>. Acesso em: 29 abr. 2019.

BITTENCOURT, Circe Maria Fernandes. Livros didáticos entre textos e imagens. In: BITTENCOURT, Circe Maria Fernandes. O saber histórico na sala de aula. 12. ed. São Paulo: Contexto, 2015. p. 69-90.

BOCCHINI, Maria Otilia. Legibilidade visual e projeto gráfico na avaliação de livros didáticos pelo PNLD. Anais do Simpósio Internacional Livro Didático, Educação e História. São Paulo, Faculdade de Educação USP, 2007.

BOESCH GAJANO, Sofia. Santidade. In: LE GOFF, Jacques e SCHMITT, Jean-Claude (Dir.). Dicionário temático do Ocidente Medieval. Bauru, SP: Edusc, v.2, 2002, p.449- 463.

BUENO, João Batista. Imagens visuais em livros didáticos de História. Resgate: Revista Interdisciplinar de Cultura, Campinas, v. 19, n. 22, p.68-76, jul./dez. 2011. 


\section{artigos}

Análise Comparativa do Uso das Imagens em Livros Didáticos com Conteúdo de História Medieval

CUNHA, Maria de Fátima da; XAVIER, Erica da Silva. Entre a indústria editorial, a academia e o estado: o livro didático de história em questão. Cadernos do Ceom: Arquivos e tecnologias digitais, Santa Catarina, Ano 25, v. 24, n. 34, p.123-146, jun. 2011. Disponível em: <https://bell.unochapeco.edu.br/revistas/index.php/rcc/article/view/971/540>. Acesso em: 29 abr. 2019.

DELEGÁ, Etson. O Papel da Imagem no Livro Didático. Jornal da Educação, 2012.

FERRARO, Juliana Ricarte. A produção dos livros didáticos: uma reflexão sobre imagem, texto e autoria. Cadernos do Ceom, Chapecó, v. 24, n. 34, p.169-188, 2011.

GERMINARI, Geyso D.; MOURA, Anderson Fagundes de. Livro didático de história, entre conteúdos e epistemologia. Educação Unisinos, São Leopoldo, v. 21, n. 1, p.102-110, jan./abr. 2017.

Disponível

em:

<http://revistas.unisinos.br/index.php/educacao/article/view/edu.2017.211.11/5858>. Acesso em: 29 abr. 2019.

LITZ, Valesca Giordano. O uso da imagem no Ensino de História. Caderno Pedagógico Universidade Federal do Paraná, Curitiba, 2009.

LOHN, Reinaldo Lindolfo; MACHADO, Vanderlei. Gênero e imagem: relações de gênero através das imagens dos livros didáticos de história. Revista Gênero, Niterói, v. 4, n. 2, p.119134, 2004.

OLIM, Bárbara Barros de. Imagens em livros didáticos de história das séries iniciais: uma análise comparativa e avaliadora. Outros Tempos, Maranhão, v. 7, p.93-118, dez. 2010.

OLIVEIRA, Esdras Carlos. As relações do livro didático de História com historiografia e Teoria da História, analisando as coleções integralis (IBEP) e História - cultura e sociedade (FTD). Revista Labirinto: Ano XVI, Rondônia, v. 24, n. 1, p.81-99, 30 jul. 2016. Disponível em: <http://www.periodicos.unir.br/index.php/LABIRINTO/article/view/1687/1610>. Acesso em: 29 abr. 2019.

SCHMITT, Jean-Claude. As relíquias e as imagens. In: Id. O Corpo das Imagens. Ensaios sobre a cultura visual no Ocidente medieval. Bauru: Edusc, 2007. p. 279-299.

SCHMITT, Jean-Claude. Imagens. In: SCHMITT, Jean-Claude; GOFF, Jacques Le. Dicionário Temático do Ocidente Medieval. São Paulo: Edusc, 2006. p. 591-605.

SISTEMA ANGLO. Ensino anglo. Disponível em: <http://www.sistemaanglo.com.br/>. Acesso em: 05 jun. 2018 